ORIGINAL ARTICLE

\section{Limbal Stem-Cell Therapy and Long-Term Corneal Regeneration}

\author{
Paolo Rama, M.D., Stanislav Matuska, M.D., Giorgio Paganoni, M.D., \\ Alessandra Spinelli, M.D., Michele De Luca, M.D., and Graziella Pellegrini, Ph.D.
}

ABSTRACT

\section{BACKGROUND}

Corneal renewal and repair are mediated by stem cells of the limbus, the narrow zone between the cornea and the bulbar conjunctiva. Ocular burns may destroy the limbus, causing limbal stem-cell deficiency. We investigated the long-term clinical results of cell therapy in patients with burn-related corneal destruction associated with limbal stem-cell deficiency, a highly disabling ocular disease.

\section{METHODS}

We used autologous limbal stem cells cultivated on fibrin to treat 112 patients with corneal damage, most of whom had burn-dependent limbal stem-cell deficiency. Clinical results were assessed by means of Kaplan-Meier, Kruskal-Wallis, and univariate and multivariate logistic-regression analyses. We also assessed the clinical outcome according to the percentage of holoclone-forming stem cells, detected as cells that stain intensely (p63-bright cells) in the cultures.

\section{RESULTS}

Permanent restoration of a transparent, renewing corneal epithelium was attained in $76.6 \%$ of eyes. The failures occurred within the first year. Restored eyes remained stable over time, with up to 10 years of follow-up (mean, 2.91 \pm 1.99 ; median, 1.93). In post hoc analyses, success - that is, the generation of normal epithelium on donor stroma - was associated with the percentage of p63-bright holoclone-forming stem cells in culture. Cultures in which p63-bright cells constituted more than 3\% of the total number of clonogenic cells were associated with successful transplantation in $78 \%$ of patients. In contrast, cultures in which such cells made up 3\% or less of the total number of cells were associated with successful transplantation in only $11 \%$ of patients. Graft failure was also associated with the type of initial ocular damage and postoperative complications.

\section{CONCLUSIONS}

Cultures of limbal stem cells represent a source of cells for transplantation in the treatment of destruction of the human cornea due to burns.
From San Raffaele Scientific Institute, Ophthalmology Unit, Milan (P.R., S.M., G.P., A.S.); and the Center for Regenerative Medicine Stefano Ferrari, University of Modena and Reggio Emilia, Modena, Italy (M.D.L., G.P.). Address reprint requests to Professor Pellegrini at the Center for Regenerative Medicine Stefano Ferrari, University of Modena and Reggio Emilia, Via Glauco Gottardi 100, Modena, Italy, or at graziella.pellegrini@unimore.it.

This article (10.1056/NEJMoa0905955) was published on June 23, 2010, at NEJM.org.

N EngIJ Med 2010;363:147-55. Copyright (c) 2010 Massachusetts Medical Society. 
CLEAR CORNEA IS ESSENTIAL TO VISUAL acuity and depends on stromal avascularity and epithelial integrity. ${ }^{1}$ Corneal renewal and repair are mediated by stem cells of the limbus, the narrow zone between the cornea and the bulbar conjunctiva. ${ }^{2}$ Ocular burns may destroy the limbus, causing limbal stem-cell deficiency. In such cases, the cornea acquires an epithelium through the invasion of bulbar conjunctival cells. This process leads to neovascularization, chronic inflammation, and stromal scarring, with corneal opacity and loss of vision. ${ }^{3}$ Allogeneic corneal transplantation (keratoplasty) restores transparency temporarily, but eventually, the conjunctival cells begin to invade and resurface the cornea. The only way to prevent this invasion is to restore the limbus. Such restoration has been attained in cases of unilateral limbal stem-cell deficiency through the grafting of limbal fragments obtained from the uninjured eye. ${ }^{4}$

Under appropriate culture conditions, human keratinocytes generate holoclones, meroclones, and paraclones, all of which are capable of proliferation. ${ }^{5}$ Holoclone-forming cells are the stem cells of virtually all human squamous epitheliaa $2,6,7$ and are required to permanently restore massive epithelial defects. ${ }^{6-8}$ In humans, holoclone-forming cells are located in the limbus but not in the central cornea.9,10 Paraclones, which are derived from holoclones, have the properties of transient amplifying progenitor cells. ${ }^{5,9}$ Meroclones have intermediate proliferative and clonogenic potential; they give rise to and are a reservoir for paraclones. ${ }^{5,9}$

Human limbal stem cells can be identified, both in vivo and in vitro, through their expression of the p63 transcription factor. ${ }^{11-13}$ The TP63 gene generates six isoforms. ${ }^{14}$ Transcription from different promoters generates two different premessenger RNAs: TAp 63 and $\Delta N p 63$. Alternative splicing of each transcript produces $\alpha, \beta$, and $\gamma$ isoforms. ${ }^{14}$ Ocular keratinocytes may contain all the $\Delta \mathrm{N}$ isoforms, but $\Delta \mathrm{Np} 63 \alpha$ (hereafter referred to as p63) is by far the most abundant ${ }^{11,12}$; it is present in the limbus but not in the uninjured central cornea ${ }^{12,13}$ and is expressed in holoclones but not in paraclones. ${ }^{12}$ The protein p63 sustains the proliferative potential of limbal stem cells, and the $\mathrm{C} / \mathrm{EBP} \delta$ transcription factor maintains the self-renewal of these cells and regulates their mitotic rate. ${ }^{13}$ During corneal repair, limbal stem cells that stain intensely (hereafter referred to as p63-bright cells) are released from $\mathrm{C} / \mathrm{EBP} \delta$ dependent mitotic constraints, multiply, and $\mathrm{mi-}$ grate to regenerate corneal epithelium. ${ }^{13}$

The finding that human limbal cell cultures ${ }^{15}$ contain holoclones ${ }^{9}$ led to the first therapeutic use of such cultures in the regeneration of corneal epithelium. ${ }^{16}$ Autologous limbal cell cultures also offer an opportunity to treat patients who have severe bilateral loss of corneal epithelium, provided that a tiny part of the limbus is spared in one of the two eyes; thus, it is not applicable in cases of total bilateral limbal stem-cell deficiency. Related studies have been reported, ${ }^{6,17}$ but they have been limited because of the comparatively small numbers of cases, the relatively short follow-up, and the heterogeneity among causes of the disorders and among the sources of transplants and cell cultures. We report the long-term results of a study in which we used this approach to treat patients with corneal damage from common causes.

METHODS

\section{PATIENTS}

Patients with severe or total, unilateral or partial burn-related lateral limbal stem-cell deficiency were included in the study. (For details, see Table 1 in the Supplementary Appendix, available with the full text of this article at NEJM.org.)

\section{CELL CULTURE AND TREATMENT}

Autologous limbal stem cells were obtained from a biopsy specimen ( 1 to $2 \mathrm{~mm}^{2}$ ) taken from the patient's contralateral eye, and the cells were cultured on fibrin, a natural substrate that preserves holoclone-forming cells. ${ }^{18-20}$ Clinical-grade-certified, lethally irradiated 3T3-J2 cells from a master cell bank were used as feeder cells. Details of cell culture, graft preparations, immunohistochemical tests, and surgical and postoperative procedures are described in the Supplementary Appendix.

\section{FOLLOW-UP AND ASSESSMENT OF OUTCOME}

Follow-up evaluations were performed according to standard procedures; for details, see the Supplementary Appendix. The outcome of treatment was assessed at 1 year. The treatment was considered to be successful if all symptoms had disappeared and a transparent, avascular, and stable corneal surface had been restored and was con- 
sidered to be partially successful if most symptoms had disappeared but superficial neovascularization had recurred, even if it was not as extensive as at the time of admission. Treatment failure was defined as the presence of symptoms, recurrent epithelial defects, pannus, and inflammation at 1 year. Three observers assessed the clinical results; two were involved in the patients' care, and the third did not participate in any biologic or clinical procedure.

\section{STATISTICAL ANALYSIS}

We analyzed results with the use of the KaplanMeier, chi-square, Mann-Whitney, McNemar, and Kruskal-Wallis tests as well as univariate and multivariate stepwise logistic-regression analyses (as described in the Supplementary Appendix).

\section{RESULTS}

\section{CHARACTERISTICS OF THE PATIENTS}

We studied 113 eyes from 112 patients enrolled between 1998 and 2006. The mean ( \pm SD) age of the patients was $46.5 \pm 14.4$ years (range, 14 to 80 ), and $78.6 \%$ of them were men. The limbal stemcell deficiency ranged from severe (in 35.4\% of the patients) to total (in 64.6\%) (Table 1 in the Supplementary Appendix). The most common causes of limbal stem-cell deficiency (in $97.3 \%$ of cases) were chemical burns (83 alkali, 16 acid, and 4 other) and thermal burns (7). Two patients had a bacterial infection and one patient had undergone orbit irradiation. Patients had unilateral $(87.5 \%)$ or bilateral $(12.5 \%)$ burns; only two patients had bilateral severe limbal stem-cell deficiency (Patients 24 and 83 in Table 1 in the Supplementary Appendix). Most of the eyes (84\%) had been treated previously with surgery (in some cases multiple surgeries), but all surgical treatments had failed, probably because of an insufficient number of residual limbal stem cells to regenerate corneal epithelium. Twenty-eight patients had undergone a single unsuccessful keratoplasty, and 20 had undergone multiple unsuccessful keratoplasties. Before this study, optimally corrected visual acuity was less than 0.1 (i.e., light perception, hand movement, and counting fingers) in $88.5 \%$ of the patients and was 0.1 to 0.5 in $11.5 \%$ of the patients. The baseline features of the patients, including diagnoses and grading of limbal stem-cell deficiency, are provided in the Supplementary Appendix.

\section{GRAFTS}

A total of 125 cultures were grafted in 113 eyes (112 patients) between July 1998 and December 2007. These included a bilateral graft in Patient 24 plus 12 regrafts. Both eyes of Patient 24 and the left eye of Patient 83 were grafted with cultures prepared from a single biopsy specimen taken from a spared limbal area.

The clinical outcome of limbal stem-cell transplantation was judged to be successful in $76.6 \%$ of the eyes (Table 1 ).

The mean time between injury and the first graft was $18.3 \pm 16.7$ years (median, 12.9; range, 0.8 to 56.4). No intraoperative complications were reported. Postoperative adverse events included hemorrhage (in 12 patients), residual fibrin on the third postoperative day (in 11 patients), inflammation (in 59 patients), blepharitis with epithelial involvement (in 35 patients), and herpetic keratitis (in 3 patients) (Table 1 in the Supplementary Appendix), all of which were treated with the use of standard therapy.

\section{REGENERATION OF CORNEAL EPITHELIUM}

The human corneal epithelium is renewed approximately every 9 to 12 months. ${ }^{1}$ Since we therefore surmised that the regenerated epithelium would

\begin{tabular}{|lcccc|}
\hline \multicolumn{4}{l}{ Table 1. Clinical Outcomes of Limbal Stem-Cell Grafts in 112 Patients.* } & \\
\hline Variable & $\begin{array}{c}\text { Number } \\
\text { of Eyes }\end{array}$ & Success & $\begin{array}{c}\text { Partial } \\
\text { Success } \\
\text { number of eyes (percent) }\end{array}$ & Failure \\
Outcome of first graft & 107 & $73(68.2)$ & $18(16.8)$ & $16(15.0)$ \\
Outcome of subsequent graft & 12 & $9(75.0)$ & $2(16.7)$ & $1(8.3)$ \\
Final outcome & 107 & $82(76.6)$ & $14(13.1)$ & $11(10.3)$ \\
\hline
\end{tabular}

* Six of the 112 patients were excluded because they did not complete the study. One patient had bilateral limbal stemcell deficiency and received two grafts. 


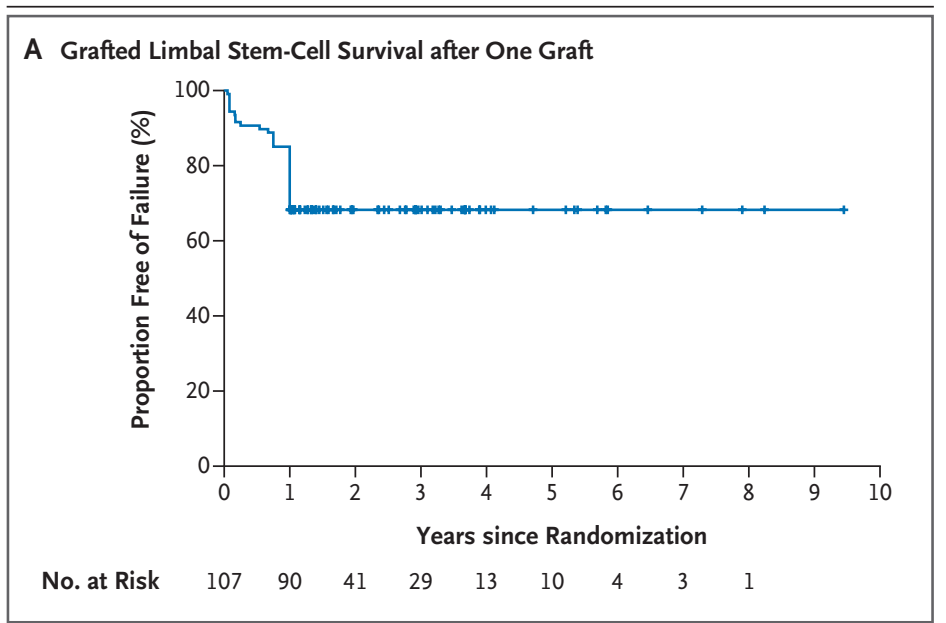

B Grafted Limbal Stem-Cell Survival after More Than One Graft

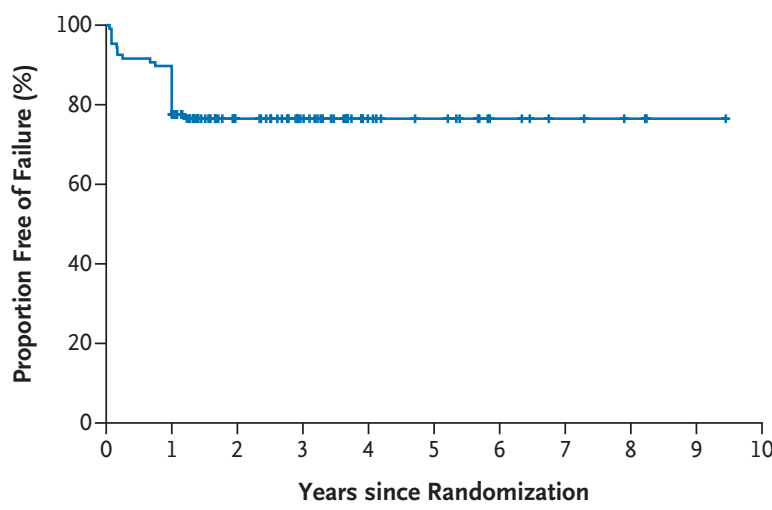

$\begin{array}{llllllllll}\text { No. at Risk } & 107 & 95 & 50 & 36 & 18 & 14 & 7 & 4 & 2\end{array}$

Figure 1. Kaplan-Meier Estimates of Grafted Limbal Stem-Cell Survival.

Panel A shows the survival estimates for the cultures after one graft was placed, with partial or total success attained in $68.2 \%$ of the eyes treated. Panel B shows survival estimates after a second graft was placed in 11 eyes (a total of 12 additional grafts, since 1 eye was regrafted twice), indicating either partial success or failure. After regrafting, 9 of these eyes regenerated normal epithelium. Thus, the final clinical outcome was deemed a success in $76.6 \%$ of the eyes treated. All failures occurred within the first year after grafting, whereas successful cultures remained stable for up to 10 years of follow-up. eyes (68.2\%), 18 eyes $(16.8 \%)$, and 16 eyes (15\%), respectively (Table 1). Of 11 eyes (representing 12 grafts, since 1 eye was regrafted twice), 6 were partially successful and 5 were considered to have failed; these 11 were all regrafted with cultures prepared from frozen cells taken from the original biopsy specimen or from cells cultured from a new biopsy specimen. In 9 of these eyes, normal epithelium was regenerated after regrafting.

Thus, the final clinical outcome was classified as a success in 82 eyes (76.6\%), a partial success in 14 eyes (13.1\%), and a failure in 11 eyes (10.3\%) (Table 1). Grafts that were considered successful at 1 year after surgery invariably remained stable thereafter, with a transparent avascular cornea covered by normal corneal epithelium (Fig. 1). Grafts that were considered failures at 1 year did not worsen in subsequent years as compared with baseline.

Univariate logistic-regression analysis showed that failures were associated with a number of factors, including age, the cause of limbal stemcell deficiency, previous surgical procedures, the severity of damage, culturing and graft-transport complications, postoperative complications, and inflammation (Table 2). On multivariate logisticregression analysis, failures were still significantly associated with the severity of damage and with culturing, graft-transport, and postoperative complications (Table 2). Post hoc analyses showed no significant difference in the likelihood of success between eyes that were also treated with keratoplasty (71\%) and eyes that were not (79\%).

\section{CRITERIA FOR GRAFTABLE LIMBAL CULTURES}

The average percentage of clonogenic cells detected in cultures was similar for successful, partially successful, and failed transplants (37.2\%, 31.1\%, and $35.5 \%$, respectively). But the percentage of colony-forming cells is inadequate as an indication of the percentage of stem cells, because it is not possible to visually identify holoclones. ${ }^{5,9}$

Determining the number of holoclones by means of clonal analysis is both cumbersome as a routine procedure ${ }^{5,9}$ and unsuitable for preoperative quality control because the results become available only after grafting. In contrast, quantitative immunodetection of p63, a marker of holoclones, is straightforward and can be performed before grafting. ${ }^{6,21}$

We were able to examine the relationship between the percentage of p63-bright cells in each culture and the clinical results in 82 patients. (We 


\begin{tabular}{|c|c|c|c|c|c|}
\hline Variable & $\begin{array}{l}\text { Successful } \\
\text { Grafts } \\
(N=73)\end{array}$ & $\begin{array}{c}\text { Partially } \\
\text { Successful } \\
\text { or Failed Grafts } \\
\quad(\mathbf{N}=34)\end{array}$ & $\begin{array}{l}\text { P Value on } \\
\text { Univariate } \\
\text { Analysis'i }\end{array}$ & $\begin{array}{c}\text { Odds Ratio } \\
(95 \% \mathrm{Cl}) \text { on } \\
\text { Multivariate } \\
\text { Analysis: }\end{array}$ & P Value \\
\hline Age $-y r$ & $49.1 \pm 14.0$ & $41.4 \pm 14.3$ & 0.02 & & \\
\hline Male sex — no. of patients (\%) & $54(74)$ & $29(85)$ & 0.23 & & \\
\hline \multicolumn{6}{|l|}{ Cause of burn — no. of eyes (\%) } \\
\hline Acid & $7(10)$ & $9(26)$ & 0.04 & & \\
\hline Alkali & $55(75)$ & $23(68)$ & & & \\
\hline Previous intervention — no. of eyes (\%) & $58(79)$ & $33(97)$ & 0.017 & & \\
\hline Severe damage - no. of eyes (\%) & $41(56)$ & $28(82)$ & 0.008 & $4.05(1.34-12.2)$ & 0.013 \\
\hline $\begin{array}{l}\text { Culture or graft-transport complications } \\
\qquad \text { - no. of eyes (\%) }\end{array}$ & $8(11)$ & $8(24)$ & 0.089 & $3.86(1.08-13.75)$ & 0.037 \\
\hline $\begin{array}{c}\text { Postoperative complications - no. of } \\
\text { eyes (\%) }\end{array}$ & $43(59)$ & $31(91)$ & $<0.001$ & 7.64 (1.99-29.33) & 0.003 \\
\hline Inflammation — no. of eyes (\%) & $33(45)$ & $26(76)$ & $<0.003$ & & \\
\hline \multicolumn{6}{|l|}{ Follow-up period } \\
\hline \multicolumn{6}{|l|}{ Biopsy to transplantation - days } \\
\hline Median & 22.5 & 28 & 0.46 & & \\
\hline Interquartile range & $16-41$ & $17-43$ & & & \\
\hline \multicolumn{6}{|l|}{ Burn to transplantation $-\mathrm{yr}$} \\
\hline Median & 12.9 & 7.7 & 0.15 & & \\
\hline Interquartile range & $5.6-33$ & $4.8-27$ & & & \\
\hline
\end{tabular}

were unable to analyze this relationship in all patients because p63 was not found to be a marker of limbal stem cells until 2001. ${ }^{11}$ ) A post hoc Kruskal-Wallis analysis showed that cultures giving rise to successful grafts contained a significantly greater percentage of p63-bright cells than those giving rise to unsuccessful grafts $(\mathrm{P}<0.001)$ (Fig. 2A). Grafts associated with partial success were obtained from cultures with an intermediate percentage of p63-bright cells.

In additional post hoc analyses, we evaluated the clinical results according to culture status. Cultures that contained more than 3\% p63-bright cells led to successful corneal epithelial regeneration in $78 \%$ of the eyes (Fig. 2B), and only $8 \%$ and $14 \%$ of such cultures were associated with failed or partial regeneration, respectively. In contrast, cultures in which $3 \%$ or less of the cells were p63-bright were successful in only $11 \%$ of eyes and were unsuccessful or partially successful in $67 \%$ and $22 \%$ of eyes, respectively. Thus, the percentage of p63-bright cells in the culture was positively associated with the clinical outcome of limbal stem-cell grafting. These data are consistent with the finding that the human limbus contains at least $5 \%$ stem cells. ${ }^{9}$ On the basis of these data, we now use only cultures that contain more than 3\% p63-bright cells to prepare grafts.

That said, a defined percentage of stem cells is necessary but not sufficient to ensure a good clinical result. Approximately $20 \%$ of cultures that contain more than 3\% p63-bright cells were associated with failed or only partially successful treatment (Fig. 2), suggesting that other factors, such as the severity of injury and the presence or absence of complications, also influence outcome.

\section{RESTORATION OF VISUAL ACUITY}

The regeneration of normal avascular corneal epithelium was associated with amelioration of symp- 


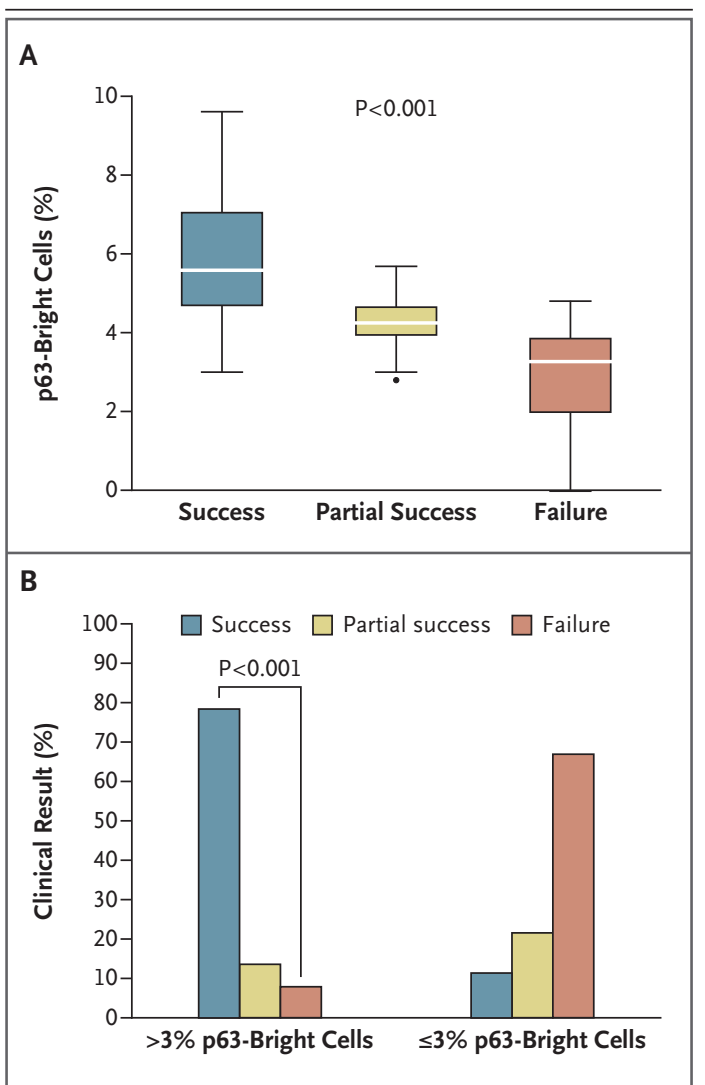

Figure 2. Relation between Clinical Results and Percentage of p63-Bright Cells in Limbal Stem-Cell Cultures.

The percentage of p63-bright cells was calculated on subconfluent primary cultures used to seed graftable secondary cultures. These analyses were performed on only 82 cultures, since the relation between p63 cells and limbal stem cells was not discovered until 2001. ${ }^{11}$ The box plots in Panel A, which are based on a Kruskal-Wallis analysis, show the relationship between the percentage of p63-bright cells and the three outcomes of success, partial success, and failure. The horizontal line within each box represents the median value; the bottom and top lines of the box represent the 25th and 75th percentiles, respectively; and the horizontal lines below and above the box represent the lowest and highest values, respectively, with outliers excluded. In Panel B, also based on a Kruskal-Wallis test, grafts scored as successes, partial successes, and failures were evaluated in relation to the percentage of p63-bright holoclone-forming cells (>3\% vs. $\leq 3 \%$ ). The cultures that contained more than 3\% p63-bright cells were successful in $78.1 \%$ of eyes and failed in $8.2 \%$ of eyes, whereas cultures that contained smaller percentages of such cells were successful in $11.1 \%$ of eyes and failed in $66.7 \%$ of eyes. Thus, the percentage of p63bright cells can be used to predict the clinical outcome of limbal stem-cell cultures. toms (burning, pain, and photophobia) in all patients whose grafts were considered successful (see Table 1 in the Supplementary Appendix). Normal vision was restored in only those patients with undamaged corneal stroma, however (Fig. 3, and Table 1 in the Supplementary Appendix). To improve the visual acuity of eyes with stromal scarring, we performed corrective surgical procedures 12 to 24 months after grafting the limbal stemcell cultures: 46 patients underwent penetrating keratoplasty $(89 \%)$, lamellar keratoplasty $(9 \%)$, or phototherapeutic keratectomy (2\%) to replace the damaged stroma. We observed no intraoperative complications and used standard therapeutic approaches for postoperative adverse events (Table 1 in the Supplementary Appendix). Histologic examination of the central cornea removed at the time of keratoplasty showed that the regenerated epithelium expressed keratin 12 (a marker of corneal epithelium) but not keratin 19 (a marker of conjunctival epithelium) (Fig. 2 in the Supplementary Appendix). We observed regeneration of the corneal epithelium that was sufficient to resurface the donor stroma in all the patients treated with keratoplasty. Permanent recovery of at least 0.6 visual acuity (range, 0.6 to 1.0 ) was attained in 21 patients (Table 1 in the Supplementary Appendix). The remaining 25 patients had partial recovery of vision (up to 0.5 visual acuity). Figure $3 \mathrm{~B}$ shows the results of limbal stem-cell grafting followed by penetrating keratoplasty in the eyes of three patients who had total limbal stem-cell deficiency, complete corneal opacification, stromal scarring, and reduced visual acuity $(<0.1$, counting fingers and perceiving hand movements) before treatment. After keratoplasty, which was performed between 4 and 6.5 years after grafting, the cornea was transparent in each of the patients and their visual acuity ranged from 0.3 to 0.9 .

Figure 3 in the Supplementary Appendix shows the eyes of Patient 24 who had severe bilateral limbal stem-cell deficiency that resulted from an alkali burn in 1948. He was treated with grafts of limbal stem-cell cultures prepared from a single biopsy specimen (taken from the left eye), followed by penetrating keratoplasty. Both corneal surfaces were restored. Follow-up at 2 years (right eye) and 5 years (left eye) showed that both eyes were stable. At follow-up his best-corrected visual acuity was 0.6 and 0.7 in the left and right eyes, respectively. 


\section{DISCUSSION}

Autologous cultures of limbal cells provide an adequate long-term source of transplant tissue for the treatment of corneal damage due to burns. We observed that a minimum of approximately 3000 stem cells, detected as p63-bright holocloneforming cells, was required to achieve clinical success. (A limbal culture contains a minimum of $3 \times 10^{5}$ cells, ${ }^{20}$ about $30 \%$ of which are clonogenic; thus, about $3 \%$ of these clonogenic cells should be holoclones.) Analysis of our findings suggested that outcomes differ significantly depending on whether the transplanted cultures contain more than 3\% p63-bright holoclone-forming stem cells or $3 \%$ or less - the success rates were $78 \%$ with the larger number of stem cells and $11 \%$ with the smaller number. On the basis of this observation, we speculate that corneal regeneration cannot be ascribed to a nonspecific stimulatory effect of epithelial cultures, fibrin, or surgical manipulation on spared residual limbal cells (if such cells are even present).

Preservation of holoclones requires culture with selected 3T3 feeder cells and fetal-calf serum, $, 0,22,23$ and this culture method has been used worldwide since the $1980 \mathrm{~s}^{6,7}$ to treat patients with massive full-thickness burns. ${ }^{18,19,24}$ During the past 30 years, no adverse effects have been reported, and this method has been approved for use in the United States, Japan, Italy, and South Korea. ${ }^{6,7}$ Retention of holoclones also requires appropriate substrates for the cultivation of cells; both fibrin and plastic have been shown to preserve holoclone-forming cells. ${ }^{18-20}$ Alternative methods involving other reagents have been proposed that obviate the use of feeder cells, serum, or both, ${ }^{6,17}$ since some investigators consider these reagents to be potentially harmful. ${ }^{25}$ The retention of stem cells when these alternative methods are used has not been investigated.

Allogeneic and buccal keratinocytes have been used as sources of grafts in previous clinical experimental studies to treat limbal stem-cell deficiency. ${ }^{6,17}$ Allogeneic keratinocytes - even when frozen or lyophilized - improve healing of partial-thickness or small skin wounds by stimulating resident cells. ${ }^{26,27}$ However, engraftment of these allogeneic cells is not permanent, ${ }^{26}$ and it seems unlikely that the presence of stem cells is required for their clinical effect. Donor epithelial cells have not been recovered from the ocular sur-

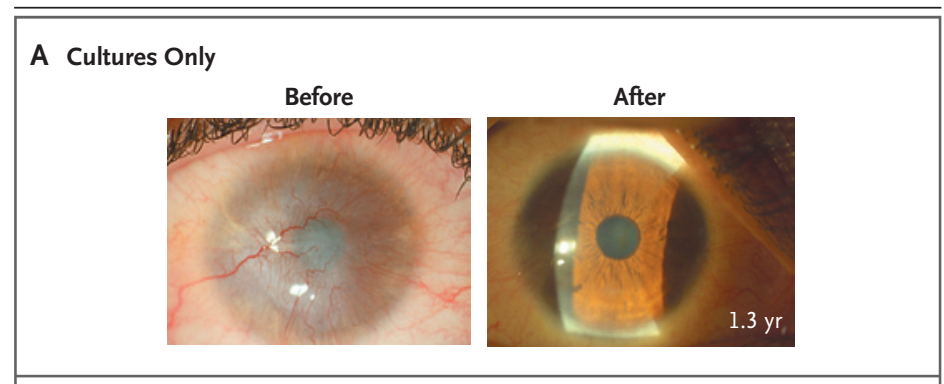

B Cultures plus Keratoplasty
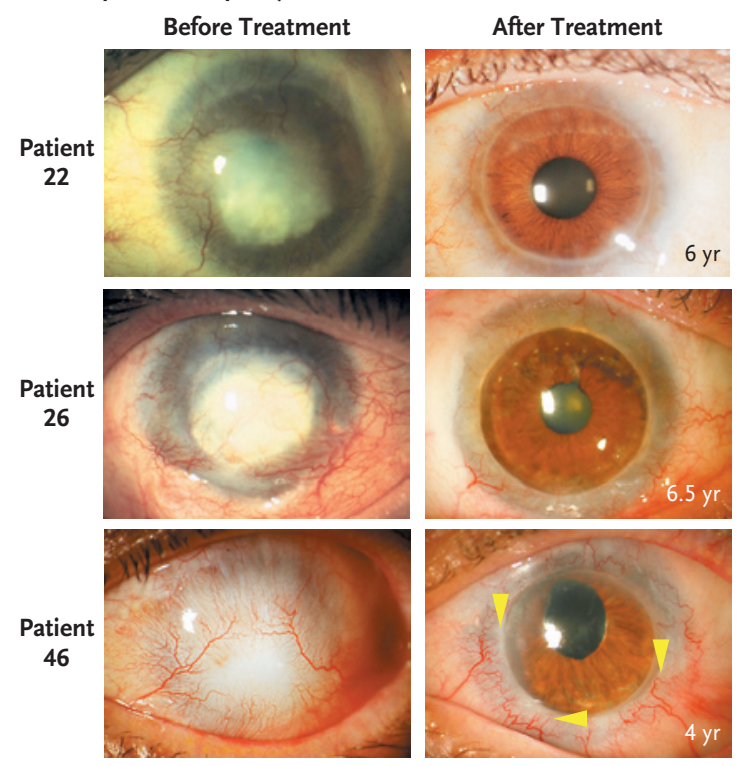

Figure 3. Regeneration of a Functional Corneal Epithelium and Restoration of Visual Acuity.

Panel A shows the left eye of Patient 93 (see Table 1 in the Supplementary Appendix, available with the full text of this article at NEJM.org), who had total limbal stem-cell deficiency due to an acid burn (image at left). His visual acuity was reduced to counting fingers. A graft of autologous limbal cultures was sufficient to regenerate functional corneal epithelium (image at right) and to restore normal vision (visual acuity, 0.7 ), since the eye had no stromal scarring. Panel B shows the eyes of Patients 22, 26, and 46 (see Table 1 in the Supplementary Appendix), which were damaged by alkali burns and were treated with unsuccessful surgery 13, 30, and 3 years before admission, respectively. All three eyes had total limbal stem-cell deficiency, complete corneal opacification, and stromal scarring (images at left). Vision was reduced to counting fingers (in Patient 22) or perceiving hand movements (in $\mathrm{Pa}$ tients 26 and 46). In all three patients, autologous limbal stem-cell cultures successfully regenerated functional corneal epithelium. To improve their visual acuity after grafting, the patients underwent penetrating keratoplasty. In all three eyes, the engrafted limbal stem cells resurfaced the donor stroma. At the last follow-up visits (at 6, 6.5, and 4 years, respectively), all eyes were covered by stable corneal epithelium (images at right). The keratoplasty resulted in complete restoration of visual acuity in Patients 22 and 46 ( 0.9 and 0.8 , respectively). The visual acuity of Patient 26 increased to only 0.3 because of a concomitant amblyopia (the alkali burn had occurred 30 years before admission). In Patient 46, the follow-up image shows that the conjunctival vessels stop at the conjunctival-corneal boundary (arrowheads); they do not invade the restored corneal surface. 
face in studies that looked at long-term outcomes, ${ }^{28,29}$ and it seems unlikely that these cells would regenerate functional epithelium in patients with total limbal stem-cell deficiency, nor is there evidence that buccal keratinocytes can generate bona fide corneal epithelium. ${ }^{30}$ If limbal stem-cell deficiency is only partial, allogeneic or oral keratinocytes may be sufficient to stimulate resident limbal cells to regenerate corneal epithelium. Additional studies to test this hypothesis are warranted. The same argument might hold true for the effect of autologous cultures on corneal regeneration. Nevertheless, the association that we observed - between the percentage of p63-bright cells and clinical success - was never related to a nonspecific stimulatory effect of the transplanted culture on resident stem cells.

In conclusion, our study shows that in patients with limbal stem-cell deficiency who received cultured limbal stem-cell grafts for corneal transplantation, the clinical results were successful at up to 10 years (at a median of 2 years) in more than $75 \%$ of the patients treated. Cultures of limbal stem cells thus represent a source of cells for transplantation in the treatment of burn-induced destruction of the human cornea.

Supported by grants from the Italian Ministry for Education, University and Research and Ministry of Health; l'Association Française contre les Myopathies et les Maladies Neuromusculaires (AFM) Telethon; the European Commission Sixth Framework Program for Research and Technological Development (corneal engineering) and Seventh Framework Program; Optimization of Stem Cell Therapy for Degenerative Epithelial and Muscle Diseases (OptiStem, HEALTH-F5-2009-223098); Regione Emilia-Romagna (area 1b, medicina rigenerativa); and the Italian Ministry of Health.

Disclosure forms provided by the authors are available with the full text of this article at NEJM.org.

This article is dedicated to the memory of Professor Stefano Ferrari, whose inspiring passion and commitment to excellence in science and education brought about the Center for Regenerative Medicine, and also to Professor Giovanni Rama, who was involved in the first phase of the project.

We thank Dr. Howard Green (Harvard Medical School, Boston) for providing the original 3T3-J2 feeder cells; Patrizia Paterna and Sergio Bondanza (Istituto Dermopatico dell'Immacolata [IDI]), and Marina Bertolin, Luca Canton, Alessandro Chiarello, Barbara Ferrari, Daniela Ferrari, Valeria Leuci, and Erika Nizza (Veneto Eye Bank Foundation [FBOV]) for their assistance with cell culture; Osvaldo Golisano (IDI) and Enzo Di Iorio and Vanessa Barbaro (FBOV) for immunohistochemical testing; and Giliola Calori and Laura Angelici for statistical analyses.

\section{REFERENCES}

1. Wagoner MD. Chemical injuries of the eye: current concepts in pathophysiology and therapy. Surv Ophthalmol 1997; 41:275-313.

2. Pellegrini G, Rama P, Mavilio F, De Luca $M$. Epithelial stem cells in corneal regeneration and epidermal gene therapy. J Pathol 2009;217:217-28.

3. Dua HS, Azuara-Blanco A. Limbal stem cells of the corneal epithelium. Surv Ophthalmol 2000;44:415-25.

4. Kenyon KR, Tseng SC. Limbal autograft transplantation for ocular surface disorders. Ophthalmology 1989;96:709-23. 5. Barrandon Y, Green H. Three clonal types of keratinocyte with different capacities for multiplication. Proc Natl Acad Sci U S A 1987;84:2302-6.

6. De Luca M, Pellegrini G, Green H. Regeneration of squamous epithelia from stem cells of cultured grafts. Regen Med 2006;1:45-57.

7. Green $H$. The birth of therapy with cultured cells. Bioessays 2008;30:897-903. 8. Mavilio F, Pellegrini G, Ferrari S, et al. Correction of junctional epidermolysis bullosa by transplantation of genetically modified epidermal stem cells. Nat Med 2006;12:1397-402.

9. Pellegrini G, Golisano O, Paterna P, et al. Location and clonal analysis of stem cells and their differentiated progeny in the human ocular surface. J Cell Biol 1999;145:769-82.

10. Majo F, Rochat A, Nicolas M, Jaoudé
GA, Barrandon Y. Oligopotent stem cells are distributed throughout the mammalian ocular surface. Nature 2008;456:250-4. 11. Pellegrini G, Dellambra E, Golisano $\mathrm{O}$, et al. p63 Identifies keratinocyte stem cells. Proc Natl Acad Sci U S A 2001; 98:3156-61.

12. Di Iorio E, Barbaro V, Ruzza A, Ponzin D, Pellegrini G, De Luca M. Isoforms of DeltaNp63 and the migration of ocular limbal cells in human corneal regeneration. Proc Natl Acad Sci U S A 2005; 102:9523-8.

13. Barbaro V, Testa A, Di Iorio E, Mavilio F, Pellegrini G, De Luca M. C/EBPdelta regulates cell cycle and self-renewal of human limbal stem cells. J Cell Biol 2007; 177:1037-49.

14. Yang A, Kaghad M, Wang Y, et al. p63, A p53 homolog at 3q27-29, encodes multiple products with transactivating, deathinducing, and dominant-negative activities. Mol Cell 1998;2:305-16.

15. Lindberg K, Brown ME, Chaves HV, Kenyon KR, Rheinwald JG. In vitro propagation of human ocular surface epithelial cells for transplantation. Invest Ophthalmol Vis Sci 1993;34:2672-9.

16. Pellegrini G, Traverso CE, Franzi AT, Zingirian M, Cancedda R, De Luca M. Long-term restoration of damaged corneal surfaces with autologous cultivated corneal epithelium. Lancet 1997;349:990-3.

17. Shortt AJ, Secker GA, Notara MD, et al. Transplantation of ex vivo cultured limbal epithelial stem cells: a review of techniques and clinical results. Surv Ophthalmol 2007;52:483-502.

18. Pellegrini G, Ranno R, Stracuzzi G, et al. The control of epidermal stem cells (holoclones) in the treatment of massive full-thickness burns with autologous keratinocytes cultured on fibrin. Transplantation 1999;68:868-79.

19. Ronfard V, Rives JM, Neveux Y, Carsin $\mathrm{H}$, Barrandon Y. Long-term regeneration of human epidermis on third degree burns transplanted with autologous cultured epithelium grown on a fibrin matrix. Transplantation 2000;70:1588-98.

20. Rama P, Bonini S, Lambiase A, et al. Autologous fibrin-cultured limbal stem cells permanently restore the corneal surface of patients with total limbal stem cell deficiency. Transplantation 2001;72:147885.

21. Di Iorio E, Barbaro V, Ferrari S, Ortolani C, De Luca M, Pellegrini G. Q-FIHC: quantification of fluorescence immunohistochemistry to analyse p63 isoforms and cell cycle phases in human limbal stem cells. Microsc Res Tech 2006;69:983-91.

22. Rheinwald JG, Green H. Serial cultivation of strains of human epidermal keratinocytes: the formation of keratinizing colonies from single cells. Cell 1975;6:33143.

23. Green $\mathrm{H}$, Kehinde $\mathrm{O}$, Thomas J. Growth of cultured human epidermal cells into multiple epithelia suitable for graft- 
ing. Proc Natl Acad Sci U S A 1979;76: 5665-8.

24. Gallico GG III, O'Connor NE, Compton CC, Kehinde O, Green H. Permanent coverage of large burn wounds with autologous cultured human epithelium. N Eng J Med 1984;311:448-51.

25. Schwab IR, Johnson NT, Harkin DG Inherent risks associated with manufacture of bioengineered ocular surface tissue. Arch Ophthalmol 2006;124:1734-40.

26. De Luca M, Albanese E, Bondanza S, et al. Multicentre experience in the treatment of burns with autologous and allogenic cultured epithelium, fresh or preserved in a frozen state. Burns 1989;15: 303-9.

27. De Luca M, Albanese E, Cancedda $R$, et al. Treatment of leg ulcers with cryopreserved allogeneic cultured epithelium: a multicenter study. Arch Dermatol 1992; 128:633-8.

28. Henderson TR, Coster DJ, Williams KA. The long term outcome of limbal al- lografts: the search for surviving cells. Br J Ophthalmol 2001;85:604-9.

29. Daya SM, Watson A, Sharpe JR, et al. Outcomes and DNA analysis of ex vivo expanded stem cell allograft for ocular surface reconstruction. Ophthalmology 2005; 112:470-7.

30. Pellegrini G. Changing the cell source in cell therapy? N Engl J Med 2004;351: 1170-2.

Copyright (๑) 2010 Massachusetts Medical Society.

RECEIVE IMMEDIATE NOTIFICATION WHEN

A JOURNAL ARTICLE IS RELEASED EARLY

To be notified when an article is released early on the Web and to receive the table of contents of the Journal by e-mail every Wednesday evening, sign up through our Web site at NEJM.org. 